\title{
ANÁLISE DA VARIABILIADE DA TEMPERATURA DO AR E DA PRECIPITAÇÃO NO DISTRITO FEDERAL NO PERÍODO DE 1965/2003 E SUA RELAÇÃO COM UMA POSSÍVEL ALTERAÇÃo CLIMÁTICA
}

\author{
Ercília Torres Steinke ${ }^{1,2}$, Giselle de Andrade Souza ${ }^{3}$ e Carlos Hiroo Saito ${ }^{4}$
}

\begin{abstract}
RESUMO
O Distrito Federal apresenta problemas ambientais e sociais característicos de metrópoles consolidadas. A elevada taxa de urbanização tem sido apontada como a causadora dos principais problemas, inclusive daqueles relacionados ao clima. Este artigo apresenta os resultados de investigação preliminar da variabilidade dos parâmetros climáticos - temperatura do ar e precipitação - no Distrito Federal, no período de 38 anos, com a finalidade principal de elucidar questões relacionadas a uma possível alteração no clima da região. É parte integrante da Tese de Doutorado "Considerações sobre variabilidade e mudança climática no Distrito Federal, repercussões nos recursos hídricos e a informação ao grande público", defendida no Programa de Pós-Graduação em Ecologia da Universidade de Brasília - UnB.
\end{abstract}

Palavras chave: variabilidade climática, Distrito Federal, temperatura do ar, precipitação.

ANALYSIS OF AIR TEMPERATURE AND PRECIPITATION VARIABILITY IN THE FEDERAL DISTRICT DURING THE 1965/2003 TIME INTERVAL AND ITS POSSIBLE RELATIONSHIP WITH A POSSIBLE CLIMATE ALTERATION

\begin{abstract}
The Federal District presents environmental and social problems that are characteristic of consolidated metropolises. The rise tax of urbanization has been pointed as the causer of the main problems, also of those related to the climate. This article presents the results of a preliminary inquiry of the variability of the climatic parameters - temperature and precipitation - in the Federal District, in the period of 38 years, with the main purpose to explain questions related to a possible alteration in the climate of the region. It is part of the Thesis "Considerations about variability and climate change in the Federal District, repercussions in the water resources and the information to the public", defended in the Ecoloy Post-Graduation Program of the University of Brasilia - UnB.
\end{abstract}

Keywords: climatic variability, Federal District, air temperature, precipitation.

1 Profa. Dra. do Departamento de Geografia da Universidade de Brasília. Laboratório de Climatologia Geográfica - LCGea, ercilia@unb.br.

2 A autora agradece a revisão do texto pela Profa . Dra. Wânia de Aragão (Depto. de Letras, UnB).

3 Formanda do Curso de Geografia da UnB, Laboratório de Climatologia Geográfica - LCGea.

4 Prof. Dr. do Departamento de Ecologia da Universidade de Brasília. saito@unb.br. 


\section{Introdução}

Muitos estudiosos do clima têm evidenciado a presença de alterações térmicas em diversas regiões do planeta Terra, admitindo a existência de uma mudança climática em nível planetário na qual os elementos - temperatura do ar e precipitação - aparecem como sendo aqueles em que mais se percebem as alterações advindas deste processo.

As definições utilizadas na literatura sobre alterações climáticas diferenciam-se de acordo com a inclusão dos efeitos antrópicos na identificação da variabilidade (TUCCI, 2002, p. 58). O Painel Intergovernamental sobre Mudança do Clima (IPCC, 2001, p. 2) define mudanças climáticas (climate change) como sendo as mudanças temporais do clima devido à variabilidade natural e/ou ao resultado de atividades humanas. Outros autores adotam, para o mesmo termo, a definição de mudanças - associadas direta ou indiretamente às atividades humanas - que alterem a variabilidade climática natural observada em determinado período.

De forma geral, o termo "variabilidade climática" é utilizado para descrever variações do clima em função dos condicionantes naturais do Planeta e suas interações, daí a denominação de "variabilidade natural do clima". Já as "mudanças climáticas" seriam as alterações na variabilidade natural do clima devido às atividades humanas. Dessa forma, faz-se necessário identificar se está ocorrendo alteração na variabilidade natural do clima em determinada escala para que se possa afirmar que está havendo mudança climática naquela escala.

Para a Organização Meteorológica Mundial (OMM), a evolução do comportamento atmosférico nunca é igual de um ano para outro ou mesmo de uma década para outra, podendo-se verificar flutuações a curto, médio e longo prazo. Assim, podem-se distinguir várias categorias de variação que refletem as dificuldades existentes em separar os efeitos das atividades humanas no clima e a sua variabilidade natural, sobretudo porque o sistema climático é extremamente complexo e sua dinâmica ainda não é completamente compreendida, embora se tenha avançado bastante no conhecimento sobre o sistema Terra - Atmosfera.

Utilizando-se da prerrogativa de que o aumento na quantidade de $\mathrm{CO} 2$ produz a elevação da temperatura da baixa atmosfera em um modelo de escala logarítmica, vários eventos foram organizados no sentido de discutir a problemática da mudança climática global; assim, foi implantado, em 1988, pelo Programa das Nações Unidas para o Meio Ambiente (PNUMA)e pela OMM, o Painel Intergovernamental sobre Mudança do Clima (IPCC) a fim de: (1) avaliar as informações científicas existentes sobre a mudança do clima; (2) avaliar os impactos ambientais e socioeconômicos da mudança do clima, e (3) formular estratégias de resposta a estes impactos.

O IPCC é mais conhecido por seus Relatórios de Avaliação que são amplamente reconhecidos como as fontes mais confiáveis de informações sobre a mudança do clima. Contudo, embora exista toda uma credibilidade envolvendo o IPCC - em função de nele estarem reunidos cientistas do mundo inteiro, representando diferentes áreas do conhecimento - é cada vez maior o número de cientistas que coloca em dúvida as afirmações destes Relatórios de Avaliação.

As previsões de mudanças climáticas apresentadas pelo IPCC 
baseiam-se nos resultados da aplicação de Modelos de Circulação Geral da Atmosfera (MCGAs). Tais modelos descrevem a atmosfera de forma global, empregando equações matemáticas para prescrever as leis físicas que a regem. Segundo Abreu (2000, p. 84), os modelos são importantes para que se possam avaliar as implicações de uma mudança na composição química da atmosfera. Porém, a autora ressalta o fato de os modelos atuais serem limitados pelo conhecimento científico sobre a dinâmica da atmosfera e pelos recursos computacionais disponíveis. Por esse motivo, de acordo com Brigatti e Sant 'Anna Neto (2004, p. 01), os modelos não são suficientes, não havendo concordância nas projeções em escala regional a respeito, por exemplo, do aumento da temperatura.

Cumpre lembrar que as alterações climáticas são numerosas e podem ocorrer de formas muito variadas e em diferentes escalas de tempo e de espaço. Contudo, não se devem estabelecer relações diretas entre alterações nos parâmetros climáticos locais, por exemplo, e a tão especulada mudança climática global, embora haja consenso em relação ao fato de que uma mudança climática desta magnitude produziria implicações nas escalas locais.

No caso do Distrito Federal, muito se tem especulado sobre possíveis alterações nos parâmetros climáticos em função da substituição da superfície e resultados de estudos como os de Ribeiro (2000) e Baptista (2001) apontam para uma mudança no clima. A imprensa local tem desempenhado o papel de maior disseminadora de informações referentes ao tema, sobretudo daquelas de caráter sensacionalista, tais como, a de que o Distrito Federal está entrando em um processo de desertificação irreversível (PAIXÃO, 2003, p.23). Porém, ainda não existem estudos suficientes para comprovar estatisticamente a existência de uma tendência de mudança nas séries de dados climáticos existentes no Distrito Federal.

É notório que a capital brasileira - apesar de sua concepção planejada e de seu título de "Patrimônio da Humanidade" - exibe várias evidências de não sustentabilidade de seu ambiente. A polarização exercida pela capital e a migração desencadeada têm produzido caótico quadro de degradação. Um dos fatores que mais tem contribuído para este quadro é a expansão urbana. Acredita-se que a ocupação sem planejamento pode estar afetando, de modo direto, o clima do Distrito Federal em virtude de desmatamentos - com o conseqüente asfaltamento de vias e construção de prédios - feitos para dar lugar a novos conglomerados populacionais. De acordo com o INMET (2000, p. 02), indícios de alterações climáticas no Distrito Federal podem ser verificados, por exemplo, por meio dos índices de umidade relativa do ar, que permaneceram em níveis muito baixos de 1990 a 2000.

Nesse contexto, o presente artigo apresenta os resultados de investigação preliminar da variabilidade dos parâmetros climáticos temperatura do ar e precipitação - no Distrito Federal, no período de 38 anos, com a finalidade principal de elucidar questões relacionadas a possível alteração no clima desta região, a qual carece de estudos aplicados ao clima.

\section{2. Área de estudo}

A área de estudo compreende o limite político-administrativo do Distrito Federal do Brasil, localizado na região geoeconômica do Centro-Oeste. 
Seus limites são definidos, a norte, pelo paralelo $15^{\circ} 30^{\prime}$; ao sul, pelo paralelo $16^{\circ} 03^{\prime}$ e pelos limites naturais; ao leste, pelo rio Preto; e pelo rio Descoberto, a oeste, abrangendo a área aproximada de $5.814 \mathrm{~km}^{2}$.

O relevo caracteriza-se por topografia plana a plana ondulada, com cotas entre 830 e 1.000 metros, constituindo-se nos divisores de água das bacias hidrográficas desta região. Existem, também, unidades morfológicas com relevo suave-ondulado, representadas por colinas; e as de relevo acidentado, encostas de perfil côncavo-convexo e perfil complexo. Grande parte dessas unidades está recoberta por Latossolos e Cambissolos (STEINKE, 2003, p.91).

A região é drenada por cursos d'água pertencentes a três das mais importantes bacias hidrográficas brasileiras: São Francisco, representada pelo rio Preto; Tocantins/Araguaia, pelo rio Maranhão; e Paraná, pelos rios São Bartolomeu e Descoberto. Dadas as condições dos solos, da topografia e do clima, existe grande quantidade de canais de primeira ordem e de nascentes (SEMARH, 2000).

O Distrito Federal situa-se na região do Cerrado e apresenta diferentes tipos de vegetação, tais como: Cerradão, Cerrado Típico, Campo Cerrado, Campo Sujo e Campo Limpo. Matas Ciliares, Veredas e Campos Rupestres completam o quadro (SEMARH, 2000).

Os sistemas de circulação atmosférica que atuam no Centro-Oeste, associados à posição geográfica do Distrito Federal, permitem observar, nesta região, dois períodos marcantes: um seco e outro úmido. Conforme Barros (2003, p.117), de maneira geral pode-se dizer que o período compreendido entre os meses de maio a setembro (período seco) possui as seguintes características: intensa insolação, pouca nebulosidade, forte evaporação, baixos teores de umidade no ar, pluviosidade reduzida e grande amplitude térmica (máximas elevadas e mínimas reduzidas). O inverso ocorre no semestre de outubro a abril (período úmido): a insolação reduz-se, a nebulosidade aumenta, diminui a evaporação, os teores de umidade do ar aumentam, a pluviosidade intensifica-se e a amplitude térmica moderadamente reduz-se, pois as máximas mantém-se e as mínimas elevam-se.

O Distrito Federal superou, muito cedo, as expectativas de crescimento demográfico. Em dez anos, desde a inauguração da capital, a região já havia atingido os 500.000 habitantes. De acordo com o IBGE (2000), a população total do Distrito Federal havia alcançado a marca de 2.043.169 habitantes no ano 2000. Desse modo, observa-se que o acelerado crescimento populacional e os conflitos gerados pela estrutura urbana vêm trazendo, para a região, problemas decorrentes da ocupação desordenada e da falta de planejamento urbano.

\section{Material e métodos}

Para o desenvolvimento da pesquisa foram selecionadas seis estações meteorológicas no Distrito Federal e utilizados os seguintes parâmetros climáticos: temperatura do ar e precipitação. Os dados foram gentilmente cedidos pelas seguintes instituições: Instituto Nacional de Meteorologia (INMET), EMBRAPA - Centro de Pesquisas Agropecuárias do Cerrado (CPAC/ EMBRAPA) e Centro Nacional de Pesquisas em Hortaliças (CNPH/EMBRAPA), Reserva Ecológica do IBGE (RECOR), Primeiro Centro 
Integrado de Defesa Aérea e Controle de Tráfego Aéreo (CINDACTA I), e Universidade de Brasília - Fazenda Água Limpa (FAL/UnB).

Infelizmente, nem todas as estações possuem registros desde os anos 60, ou mesmo 70, com exceção do CINDACTA I, que registra dados desde agosto de 1960; do INMET, que possui registros desde 1961; e da EMBRAPA, que possui registros: desde 1974 para o CPAC principal; desde 1971 para o $\mathrm{CNPH}$; e desde 1978 para o CPAC Chapada ${ }^{5}$. Por isso, para a definição do período homogêneo a ser estudado, optou-se por adotar um período mais curto, que contasse com número maior de observações, ao invés de um período mais longo, porém com quantidade menor de pontos de observação.

Em primeiro lugar, realizou-se a análise do comportamento da temperatura do ar e da precipitação, procurando verificar a existência e as características das inconstâncias climáticas, com base no estudo da série temporal de 1965 a 2003, referente aos dados fornecidos pelo INMET (Estação Brasília). Optou-se por esta análise pontual uma vez que a Estação do INMET é aquela que apresenta o registro de dados meteorológicos mais consistente entre as demais estações do Distrito Federal. Contudo, os quatro primeiros anos de registro apresentam muitas falhas. Por isso, optou-se por analisar os dados a partir de 1965 até 2003.

O problema de detectar se há aumento progressivo nas variáveis climáticas e de estimar seu valor é típico de análise de tendência em séries temporais ou, em outros termos, de avaliação da estacionariedade de séries temporais. Este tipo de problema é particularmente complexo em séries climatológicas, pois as variáveis climáticas apresentam flutuações significativas ao longo do tempo. Considerando esses fatores, utilizaram-se, para a análise dos parâmetros selecionados, um modelo de regressão não-linear para os dados de temperatura do ar e um modelo de regressão linear para os dados de precipitação.

Foram utilizados os dados diários de temperatura do ar em todo o período analisado (1965 - 2003) e, a partir deles, geradas as médias mensais das máximas e das mínimas - como parâmetros para esta pesquisa. Os dados foram analisados empregando-se um modelo de regressão não-linear, considerando que o comportamento das temperaturas mensais do ar, ao longo do ano, varia de forma senoidal. As curvas estimadas para cada ano foram comparadas com o ajuste não-linear da Normal Climatológica (1992) de temperatura média mensal do ar. As regressões foram calculadas seguindo o modelo:

$$
\hat{Y}_{i}=\beta_{0}+\beta_{1} \cdot x_{i}+\beta_{2} \cdot x_{i}^{2}+\beta_{3} \cdot x_{i}^{3}+\varepsilon
$$

Onde:

$\hat{Y}_{i}=$ variável dependente;

$\beta_{0}, \beta_{1}, \beta_{2}, \beta_{3}=$ parâmetros da equação;

$X_{i}=$ variável independente e

$\varepsilon=$ erro aleatório.

Para os dados de precipitação, foi aplicado um modelo de regressão

5 Os dados da Estação CHAPADA não foram utilizados devido à proximidade com a Estação CPAC Principal. 
linear, tendo em vista que estes dados são interpretados a partir do seu total anual; as curvas ajustadas foram, então, comparadas com a Normal Climatológica pelo Teste t de Student, considerando o desvio padrão dela, por meio da equação:

$$
\hat{Y}_{i}=\beta_{0}+\beta_{1} \cdot x_{i}+\varepsilon
$$

Onde:

$\widehat{Y}_{i}=$ variável dependente;

$\beta_{0}, \beta_{1}=$ parâmetros da equação;

$X_{i}=$ variável independente e

$\mathcal{E}=$ erro aleatório.

Os parâmetros $\beta_{0}$ e $\beta_{1}$ foram determinados por meio do método dos mínimos quadrados. O coeficiente $\boldsymbol{\beta}_{\mathbf{1}}$ indica a tendência da série temporal representada pela declividade da reta de regressão linear. A significância estatística da série foi verificada mediante a aplicação do teste de hipótese para o coeficiente da regressão linear $\left(\boldsymbol{\beta}_{\mathbf{1}}\right)$ dado por:

$H_{0}: \beta_{1}=0$, não existe tendência, e

$H_{0}: \beta_{1} \neq 0$, existe tendência em dado nível de significância.

A segunda parte do trabalho referiu-se à análise comparativa entre os dados das Estações Meteorológicas do INMET, CPAC, CNPH, RECOR, CINDACTA I, e FAL. A análise foi realizada mediante a aplicação do Teste $t$ de Student com nível de significância de $5 \%$, para dados dependentes entre os resultados obtidos de temperatura do ar e precipitação nas estações citadas acima e os obtidos no INMET. O objetivo dessa análise foi investigar se os dados registrados nas outras estações meteorológicas do Distrito Federal são semelhantes àqueles registrados no INMET. Para tanto, utilizou-se uma série de 19 anos (1984 - 2003).

$$
\hat{Y}_{i}=\mu+t_{i}+\varepsilon_{i}
$$

Onde:

$\hat{Y}_{i}=$ variável dependente;

$\mu=$ média geral;

$t_{i}=$ variável independente e

$\varepsilon_{i}=$ erro aleatório.

As análises foram executadas no software STATÍSTICA versão 5.2, sendo obtidos os valores médios, os coeficientes das equações, o coeficiente de determinação $\left(R^{2}\right)$ e o valor da significância. As técnicas empregadas neste trabalho são amplamente utilizadas nos estudos de Climatologia e permitem, em conjunto, estimar o relacionamento dos dados ao longo de uma seqüência temporal, com vistas na avaliação de tendência climática.

\section{Apresentação e discussão dos resultados}

A avaliação do comportamento das variáveis foi realizada mediante 
comparação dos dados registrados com as Normais Climatológicas de 1961 a 1990 (DNMET, 1992). A seguir, serão discutidos os resultados obtidos da análise dos dados da Estação do INMET, avaliando-se, separadamente, se houve alteração nos dados de temperatura do ar e precipitação para um período de 35 anos (1965 a 2003).

\section{Temperatura do ar}

Em relação às médias anuais para a temperatura do ar, no período analisado de 38 anos, os dados demonstraram que, em geral, as variações ocorreram entre $18^{\circ} \mathrm{C}$ e $22^{\circ} \mathrm{C}$, havendo alguns anos com temperaturas do ar acima da Normal Climatológica $\left(21,2^{\circ} \mathrm{C}\right)$, como observado para as médias dos anos $1983\left(22,1^{\circ} \mathrm{C}\right)$ e $1998\left(22,4^{\circ} \mathrm{C}\right)$. Este fato pode ter ocorrido devido à influência de inúmeros fatores, entre eles a ocorrência do fenômeno El Niño, que se manifestou intensamente nestes dois anos. Vale ressaltar que, quando a temperatura do ar é analisada considerando-se somente a média anual da série 1965 - 2003 e comparada com a Normal Climatológica $\left(21,2^{\circ} \mathrm{C}\right)$, observa-se tendência de aumento ao longo do período (Figura 1).

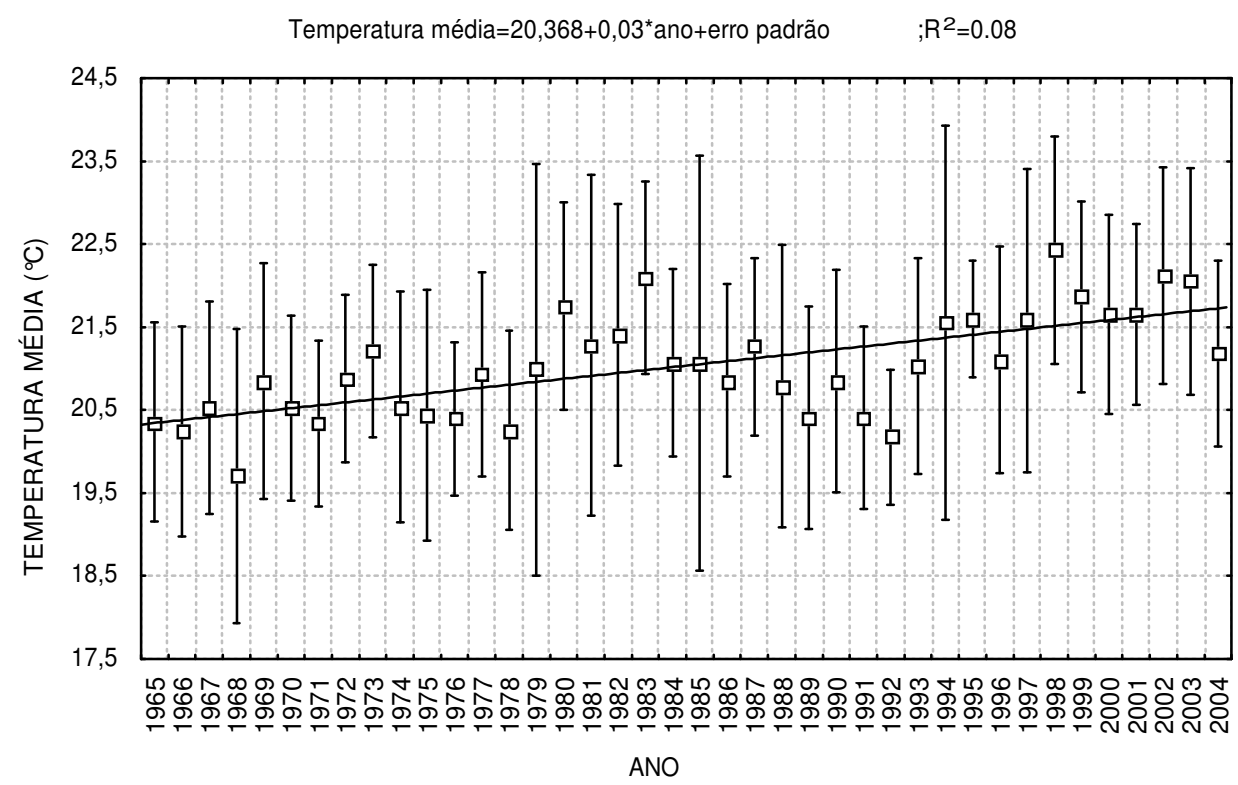

Figura 1. Média, Desvio padrão e ajuste linear da temperatura média anual de 1961 a 2003 (Temperatura média = 20,368+0,03*ano + erro padrão; $R 2=$ $0,08)$.

Porém, o valor do coeficiente de determinação $\left(R^{2}\right)$ da equação desenvolvida apresentou-se muito baixo $(0,08)$, o que mostra que a tendência de aumento identificada pela análise das médias anuais pode não se confirmar, sobretudo porque o desvio padrão da temperatura média de cada ano revelouse muito elevado. Portanto, verifica-se que utilizar dados médios de temperatura anual pode levar a uma interpretação tendenciosa do parâmetro.

O mesmo ocorre com os dados de temperatura média mensal. Analisando-se o desvio padrão da Normal Climatológica da temperatura mensal, 
observam-se variações mensais muito elevadas ao longo dos 30 anos (Figura 2).

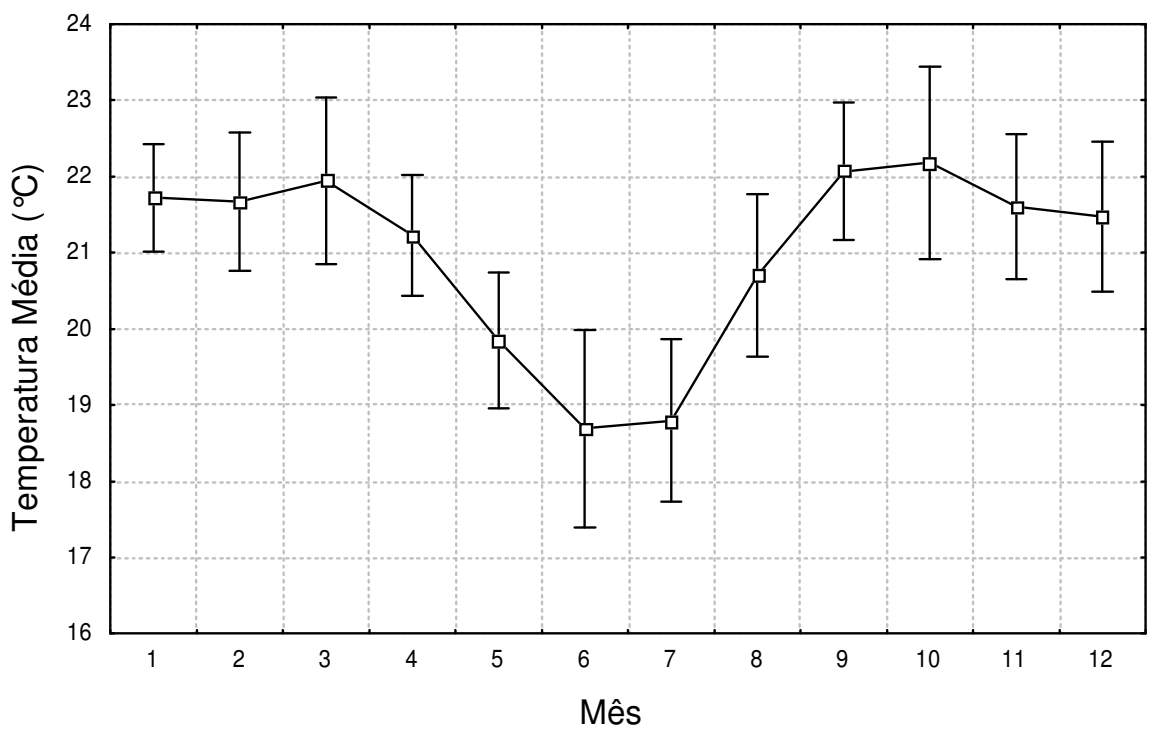

Figura 2. Normal Climatológica considerando as médias mensais e os desvios padrões mensais.

Porém, se a análise partir do pressuposto de que o comportamento da temperatura do ar não é linear, pode-se utilizar uma avaliação dos dados a partir de um modelo de regressão não-linear (senoidal) e compará-los com o ajuste aplicado à Normal Climatológica. Utilizaram-se, para tal comparação, os últimos quatro anos da série temporal por serem considerados aqueles em que a temperatura média do ar apresentou desvio positivo progressivo. Mesmo assim, observa-se que não há uma tendência de aumento da temperatura média $(p>0,05)$ na série em questão, conforme exemplificado na Figura 3.

Analisando-se a Figura 4, que mostra o comportamento das médias das máximas e das mínimas anuais de temperatura do ar, observa-se indefinição quanto à tendência, não sendo possível identificar a tendência de aumento observada no gráfico das médias anuais. É interessante notar a variação que ocorreu entre 1979 e 1985, quando as máximas aumentaram e as mínimas diminuíram, definindo um período de amplitude térmica mais elevada.

A série de 1965 - 2003 apresentou determinados anos com temperaturas médias das máximas e das mínimas anuais muito distantes da Normal Climatológica. Contudo, não se pode afirmar que houve aumento progressivo nos valores a ponto de se concluir que a temperatura do ar está aumentando.

Estes resultados contrariam o que Ribeiro (2000, p.38, 88) apresentou em sua pesquisa sobre as alterações climáticas no Distrito Federal decorrentes da urbanização. A autora concluiu que, com o processo de expansão urbana, analisado até 1998 , houve alteração positiva de $0,84^{\circ} \mathrm{C}$ na temperatura máxima absoluta, e a umidade relativa do ar média das mínimas decresceu em torno de 5,2\% na Estação do CPAC/EMBRAPA e em torno de 
$1,7 \%$ na Estação da FAL/UnB. O trabalho procurou demonstrar que as alterações na superfície decorrentes da urbanização provocaram, principalmente nos últimos anos, reflexos na temperatura e na umidade relativa do ar do Distrito Federal. Porém, não foram identificadas as formas pelas quais a urbanização provocou as alterações descritas.

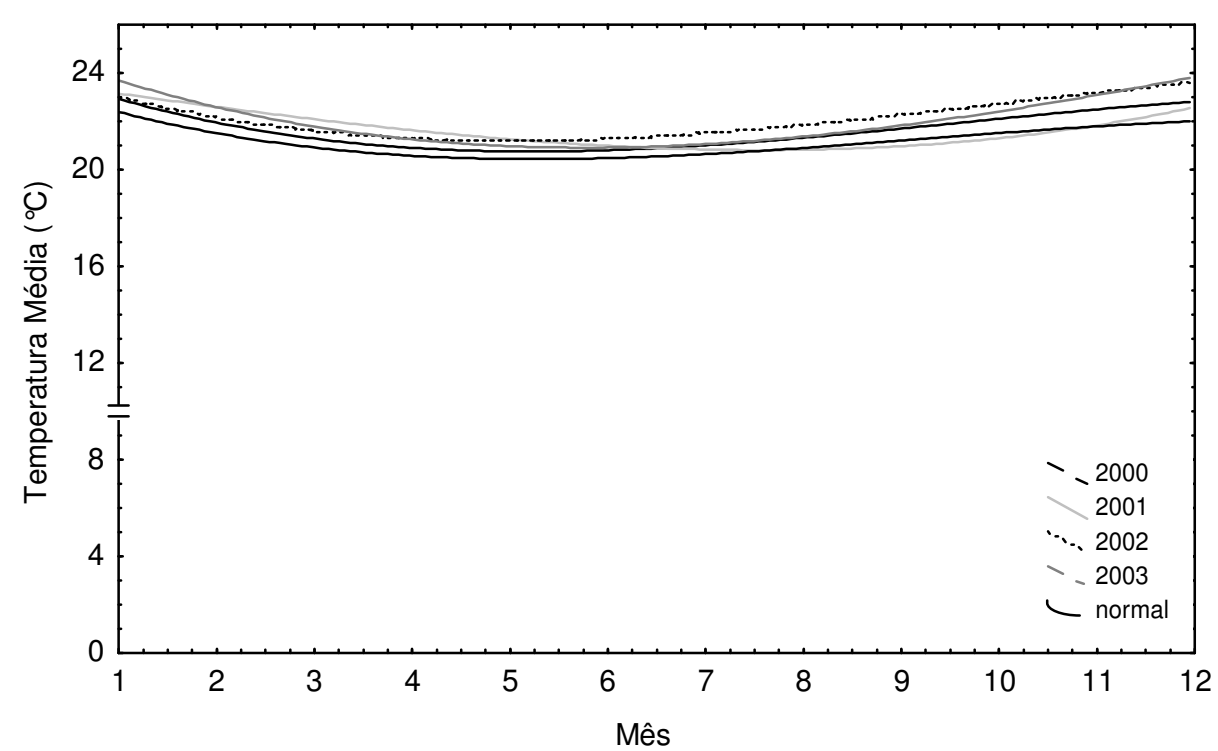

Figura 3. Ajuste não-linear da Normal Climatológica de temperatura do ar dos anos de 2000 a 2003.

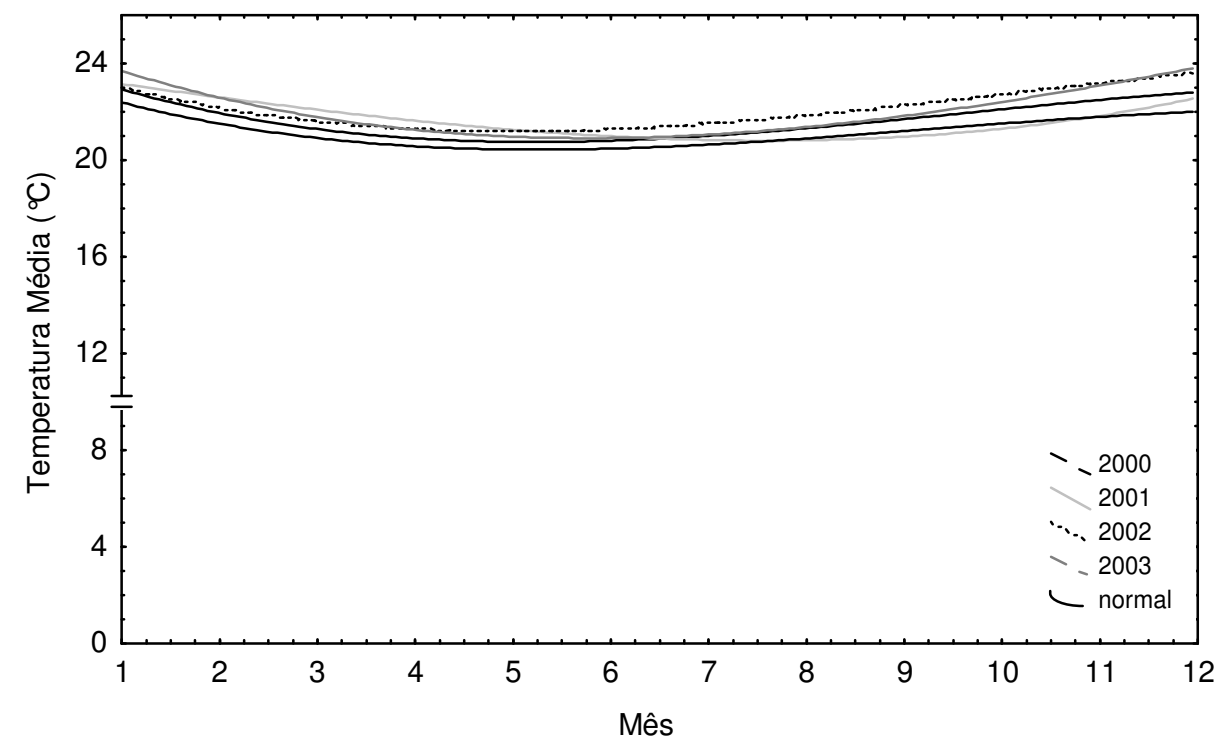

Figura 4. Temperaturas médias das mínimas e médias das máximas anuais de 1965 a 2003. 
Vale lembrar que a variabilidade dos elementos climáticos é definida por vários fatores, tais como, os episódios ENOS, a ciclicidade das manchas solares, os ciclos lunares e, até mesmo, as atividades vulcânicas. Portanto, é possível que alguns desses processos cíclicos tenham sido a causa das variações observadas na série de temperatura 1965 - 2003; porém, não se observou tendência de aumento, fato que contraria Diniz (2004), que afirma, tendo como base as temperaturas médias anuais desde 1963, que a temperatura do ar em Brasília vem nos últimos anos.

\section{Precipitação}

Com relação à precipitação anual, observou-se, na série de 1965 2003 , tendência de diminuição de $0,54 \%$ na quantidade total de chuva anual a partir do ano de $1992(p<0,05)$. Analisando-se o valor do coeficiente de determinação (R2) calculado $(0,14)$, observa-se que é muito baixo o que pode ser explicado pela grande variação ocorrida ao longo destes anos, com a ocorrência de períodos de precipitação anual superiores aos da Normal Climatológica (1985 a 1991) e períodos de precipitação inferiores aos da Normal (1972 a 1977). A partir do ano de 1993, os valores de precipitação permaneceram abaixo da Normal Climatológica; contudo, ao se observar o seu desvio padrão, verifica-se que os valores apresentados nestes anos não diferem estatisticamente $(p>0.05)$ da Normal Climatológica (Figura 5).

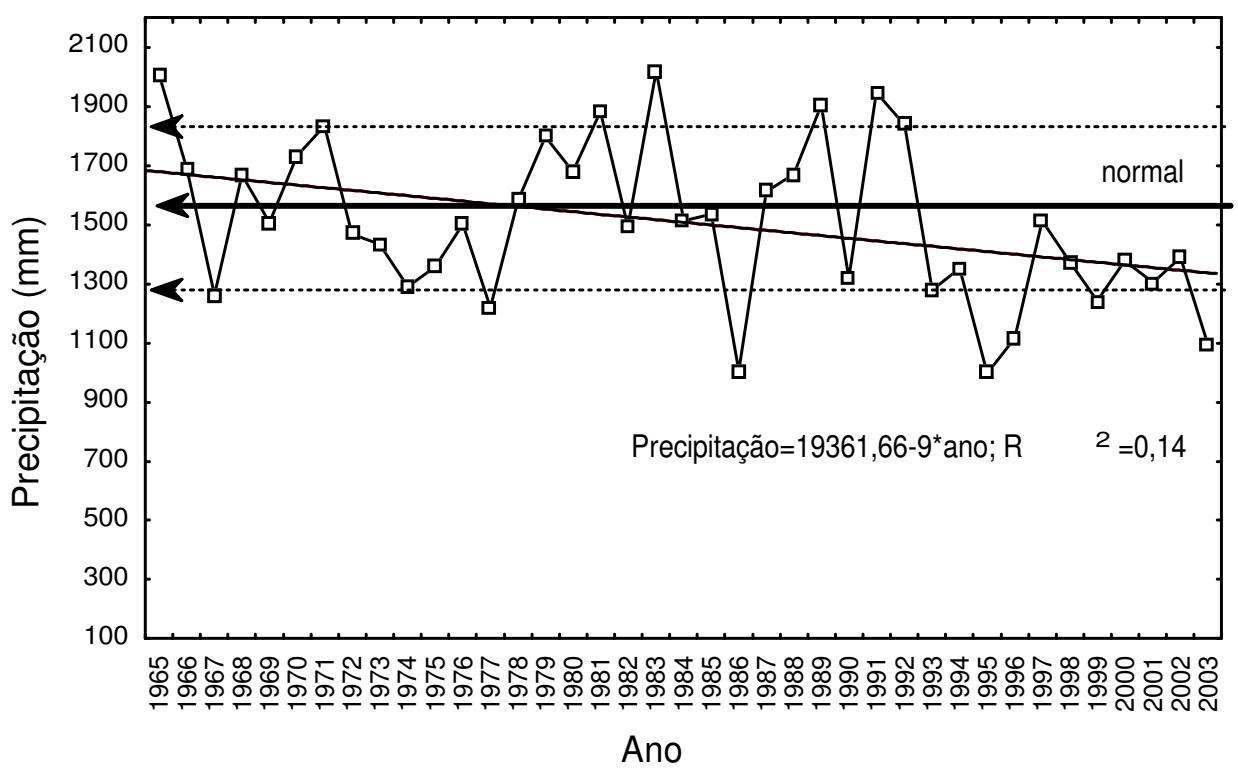

Figura 5. Precipitação anual de 1965 a 2003 ( / ), ajuste linear da precipitação anual ( , Precipitação $=19361,66-9,0 *$ ano + erro padrão; $\left.R^{2}=0,14\right)$, normal da precipitação ( $\uparrow$ ) e desvio padrão da normal ( )..

Como o valor do coeficiente de determinação $\left(R^{2}\right)$ encontrado foi muito baixo $(0,14)$, a tendência de diminuição da precipitação observada pode não significar que, necessariamente, esteja havendo modificação na precipitação. Observa-se que o comportamento pluviométrico em relação à 
Normal Climatológica $(1560 \mathrm{~mm})$ tem apresentado pequenos períodos anômalos que se poderão caracterizar como uma ciclicidade do comportamento deste parâmetro, com a continuidade da série histórica em questão.

Estas anomalias estão representadas na Figura 6, para o período de 1972 a 1977 (6 anos) e para 1993 a 2003 (10 anos), com flutuação pluviométrica abaixo da Normal. Mesmo em condições tão variáveis estes dois períodos estão bem caracterizados na série. As anomalias observadas no período de 1993 a 2003, de certa forma, acumularam grande déficit hídrico (STEINKE, 2004, p. 136) que se acabou refletindo em todo sistema hídrico do Distrito Federal. De acordo com Silva e D'Angiolella (2002, p. 42), o grande período de baixas precipitações foi causado pela atuação prolongada de sistemas meteorológicos na Região Sul, que provocou um bloqueio impeditivo ao avanço das frentes para as Regiões Sudeste, Centro-Oeste e Nordeste.

A possibilidade de uma ciclicidade do comportamento da precipitação, não deve ser descartada, sobretudo porque o ano de 2004 foi considerado chuvoso devido, entre outros fatores, à forte atuação da Zona de Convergência do Atlântico Sul - ZCAS, sistema meteorológico típico dos meses de verão e que se caracteriza pela formação de uma banda de nuvens que se estende desde o Brasil central até o oceano Atlântico (CPTEC, 2004, p.02), o que determinou totais mensais muito acima da Normal Climatológica. Somente os $402 \mathrm{~mm}$ registrados pelo INMET, no mês de fevereiro, corresponderam a $60 \%$ de toda a precipitação do ano de 2003 . Este fato pode significar que um novo ciclo se está iniciando, desta vez com totais de precipitação acima da Normal Climatológica.

Os resultados obtidos da análise do comportamento da precipitação na série 1965 - 2003 corroboram aqueles apresentados por Barros (2003), em sua Dissertação de Mestrado. A autora analisou dados de precipitação no Distrito Federal na série temporal de 1979 a 1997 e identificou alguns episódios pluviais de caráter habitual e excepcional para caracterizar o regime de chuvas desta região, bem como o ritmo de sucessão de alguns estados atmosféricos atuantes. Após definir as principais características do regime pluviométrico desta região e apresentar a distribuição das chuvas mensais ao longo do período estudado, a autora concluiu que não existe tendência definida de diminuição das chuvas no Distrito Federal mas, sim, variabilidade elevada com períodos anômalos.

É importante lembrar que, no momento de se identificarem as causas dessas anomalias, é necessário levantar todas as opções possíveis e, não simplesmente, atribuí-las aos efeitos do El Niño. Silva (1998) realizou estudo no qual comparou os valores de precipitação anual, de 1974 a 1997, os valores da Normal Climatológica e os anos de ocorrência de El Niños e observou que não existe um padrão característico da influência deste fenômeno na precipitação do Distrito Federal, observando que, em anos de El Niño, as precipitações estiveram tanto acima quanto abaixo da Normal Climatológica.

\section{Resultados comparativos entre as Estações Meteorológicas}

Realizou-se análise comparativa (Teste $\mathrm{t}$ ) entre os dados anuais de precipitação e os dados médios mensais de temperatura do ar de cinco Estações Meteorológicas do Distrito Federal e os dados obtidos da Estação do INMET. O objetivo desta análise foi determinar se os dados registrados nas 
outras estações são semelhantes àqueles registrados no INMET. Para isto, utilizou-se a série de 1984 -2003. O quadro 1 apresenta o resultado da aplicação do Teste t.

Quadro 1. Resultado da aplicação do Teste $t$.

\begin{tabular}{lccccc}
\hline & CPAC & CNPH & RECOR & CINDACTA I & FAL \\
\cline { 2 - 6 } Temperatura do ar & $+1^{\circ} \mathrm{C}$ & $+2^{\circ} \mathrm{C}$ & $+1^{\circ} \mathrm{C}$ & $+1^{\circ} \mathrm{C}$ & $=$ \\
Precipitação & $-10 \%$ & $=$ & $=$ & $-10 \%$ & $=$ \\
\hline
\end{tabular}

Com relação à precipitação anual, observou-se que as Estações $\mathrm{CNPH}, \mathrm{RECOR}$ e FAL apresentaram os mesmos resultados que o INMET $(p>0,05)$. Contudo, os dados provenientes das medições realizadas na Estação do CPAC e na do CINDACTA I tendem a ser $10 \%$ menores do que as realizadas no INMET $(p<0,05)$.

Para os dados de temperatura média, observou-se que, aqueles registrados na Estação do CPAC, na da RECOR e na do CINDACTA I são, em média, $1^{\circ} \mathrm{C}\left( \pm 0,6^{\circ} \mathrm{C}\right)$ superiores aos da Estação do INMET $(p<0,05)$. Na Estação do $\mathrm{CNPH}$, são cerca de $2^{\circ} \mathrm{C}\left( \pm 0,26^{\circ} \mathrm{C}\right)$ superiores $(p<0,05)$; e na Estação da $\mathrm{FAL}$ são iguais aos do INMET $(p>0,05)$.

De forma geral, percebe-se que existem diferenças nos dados entre as Estações, diferenças essas oriundas de fatores como a topografia, a proximidade com corpos d'água e a própria circulação atmosférica local. Portanto, fica claro, com base na análise comparativa realizada, que não se podem utilizar as informações do INMET (mesmo sendo o órgão oficial de Meteorologia) para o Distrito Federal como um todo, ou seja, mesmo que alterações nos parâmetros sejam identificadas nesta estação, isso não significa que elas estejam ocorrendo em outras partes do Distrito Federal.

Os resultados alcançados sugerem que não há tendência de mudança climática no Distrito Federal, uma vez que a análise dos parâmetros não demonstrou variação relevante, a ponto de caracterizar tendência definida.

Embora se admitam: que as mudanças nos parâmetros climáticos têm relação direta com as alterações na superfície; que o Distrito Federal, nos últimos 15 anos, tem apresentado uma expansão urbana; e que o crescimento das áreas urbanas interfere na vegetação e nos recursos hídricos, metodologicamente, 44 anos de dados (série do INMET) são ainda insuficientes para se detectarem movimentos cíclicos do clima, ou seja, indicar se, por exemplo, a seca - mais presente na última década - não é resultado de um ciclo, tal como se espera que seja para a precipitação. Assim, as afirmações de Bessat (2003, p. 12) podem ser aplicadas para o Distrito Federal:

(...) no momento, não é motivo para entrar em pânico: falar de uma mudança climática em um escala de tempo tão curta talvez seja um pouco prematuro: com efeito, a observação de alguma diferença de um decênio para outro pode, de fato, significar uma real mudança, mas também, uma anomalia, uma simples flutuação dentro do próprio sistema climático (...)

\section{Considerações finais}

A importância do estudo da variação do clima, seja ela natural ou 
não, reside no fato de que as condições climáticas se encontram diretamente ligadas, entre outros, aos processos hidrológicos que envolvem a dinâmica de uma bacia hidrográfica, assim como ao gerenciamento e à utilização das águas. Isto, por sua vez, afeta: assentamentos humanos; disponibilidade de água tanto em ambientes urbanos quanto em atividades rurais; desenho dos sistemas de irrigação; geração de energia hidrelétrica e diversas outras atividades. Para o Distrito Federal, este tema possui importância crucial, uma vez que a região não é favorecida em termos de recurso hídrico superficial e subterrâneo.

Nesse contexto, esta pesquisa procurou averiguar se há argumentos suficientes para se afirmar que o Distrito Federal está passando por mudança climática, visto que dados registrados pelo INMET e analisados por meteorologistas do próprio Instituto apontam para o aquecimento progressivo que se acredita ter sido provocado pela urbanização.

É necessário esclarecer que a Região Administrativa de Brasília, constituída pelo Setor Militar Urbano e pelo Plano-Piloto - onde está localizada a Estação Meteorológica do INMET, conhecida como Estação Brasília - compõe uma das 22 Regiões Administrativas (RAs) do Distrito Federal. Sendo assim, os dados meteorológicos pontuais registrados na Estação Brasília (INMET) não podem ser considerados como sendo representativos para todo o território do Distrito Federal. A pesquisa demonstrou que existe diferença entre os dados registrados nas principais Estações meteorológicas em operação no Distrito Federal.

Ainda que tenham sido observadas anomalias positivas na temperatura média do ar para os últimos anos, os resultados da análise da série histórica do INMET mostraram que não é possível, até agora, afirmar que existe uma tendência de aquecimento. Nem mesmo tendo sido identificada diminuição na quantidade de precipitação nos últimos 11 anos, pode-se afirmar que este comportamento se repetirá nos próximos anos. Portanto, mesmo em Brasília (localização da Estação do INMET), ainda não foram identificadas mudanças significativas para que se possa afirmar que está havendo alteração climática. Qualquer avaliação dependerá da continuidade da série histórica.

Além disso, existe necessidade do desenvolvimento de mais pesquisas envolvendo a participação dos fenômenos globais como, por exemplo, o aquecimento global, na dinâmica do clima do Distrito Federal, para que afirmações semelhantes à citada a seguir, estejam amparadas por fundamentação científica comprovada: "Quem sofre em Brasília durante este período de seca e calor pode até não saber o que é efeito estufa, mas sente na pele suas conseqüências". (Aquecimento castiga o planeta, 2004, p. 23).

É necessário lembrar que as mudanças relacionadas ao aquecimento global resultariam em alterações na circulação das massas de ar. Considerando que haja manutenção da posição da Terra, mantendo-se a estabilidade dos atuais pólos e da zona equatorial, ocorreriam mudanças na distribuição das temperaturas do ar e na umidade atmosférica absoluta, repercutindo nas características e na movimentação das massas de ar (CHRISTOFOLETTI, 1999, p.139).

A grande dúvida refere-se ao grau de alteração, tanto no posicionamento quanto na trajetória das massas de ar. As implicações refletirse-iam nos tipos de tempo, incidindo na variabilidade das temperaturas do ar e das precipitações, assim como na magnitude e na freqüência dos eventos. Há, 
portanto, necessidade de se estar ciente destas implicações e, também, das implicações no potencial de resiliência da estabilidade do sistema ambiental, cujas ultrapassagens levam a novo estado de equilíbrio, a novo tipo de clima ocorrendo, então, uma verdadeira mudança na categoria climática.

Os resultados apontam para o necessário aprofundamento e refinamento de estudos sobre o clima do Distrito Federal e suas alterações, bem como para a implementação de políticas públicas que visem a minimizar possíveis impactos socioambientais derivados destas alterações, se realmente estiverem ocorrendo. Apesar de todas as incertezas, reconhece-se que modificações nos parâmetros climáticos podem criar sérios problemas sociais e econômicos, principalmente em regiões vulneráveis, como as do Distrito Federal. Nesse caso, a ciência desempenha o papel de informar, aos responsáveis pelas tomadas de decisão e ao público em geral, as condições em que se encontram as investigações a respeito do tema e as incertezas que as acompanham além do papel de desenvolver metodologias de avaliação do impacto das alterações climáticas e 0 de propor medidas adaptáveis necessárias. A imprensa, por sua vez, deve contribuir com a divulgação das descobertas e das incertezas da ciência, de forma responsável e crítica.

\section{ReferênciasBibliográficas}

ABREU, M. L. de. Uso de modelos de circulação geral da atmosfera para simular o clima e a variabilidade climática. In: SANT'ANNA NETO, J. L. e ZAVATINI, J. A. (org.). Variabilidade e mudanças climáticas. Maringá: Eduem, 2000. P. 82-93.

Aquecimento castiga o planeta. Correio Braziliense, Brasília, 01 de out. de 2004. Mundo, p. 23.

BAPTISTA, G. M. de M. Estudo multitemporal do fenômeno ilhas de calor no Distrito Federal. Meio Ambiente, Brasília, n. 2, p. 03-17, 2002.

BARROS, J. R. A chuva no Distrito Federal: o regime e as excepcionalidades do ritmo. 2003. 221 f. Dissertação (mestrado em Geografia) - Instituto de Geociências e Ciências Exatas, Departamento de Geografia, Universidade Estadual Paulista, Rio Claro, 11/03/2003.

BESSAT, F. A. A mudança climática entre ciência, desafios e decisões: olhar geográfico. Terra Livre, São Paulo, v. 1, n.20, p.11-26. 2003.

BRIGATTI, N. e SANT'ANNA NETO, J. L. Variabilidade das temperaturas médias diárias de Presidente Prudente/SP no período de 1971/1999 e suas possíveis relações com o aquecimento global. In: SIMPÓSIO BRASILEIRO DE CLIMATOLOGIA GEOGRÁFICA, 6. Aracaju, 13 a 16 de outubro de 2004. Anais... Aracaju: UFS, 2004. 1 CD-ROM.

CENTRO DE PREVISÃO DE TEMPO E ESTUDOS CLIMÁTICOS (CPTEC). Infoclima: Informação climática para Abril, Maio e Junho de 2004. Disponível em: http://www.cptec.inpe.br Acesso em: 02 abr 2004.

DEPARTAMENTO NACIONAL DE METEOROLOGIA. Normais Climatológicas (1961 - 1990). Brasília: DNMET, 1992.

DINIZ, F. de A. O clima de Brasília. Brasília, 24 de março de 2004. Arquivo; disquete. Power Point. Palestra apresentada na Semana Meteorológica - INMET.

CHRISTOFOLETTI, A. Modelagem de Sistemas Ambientais. São Paulo: Edgard Blücher, 1999.

INSTITUTO BRASILEIRO DE GEOGRAFIA E ESTATÍSTICA (IBGE). Censo 2000. Disponível em: http://www.ibge.gov.br Acesso em: 23 jan 2004.

Intergovernmental Panel on Climatic Change. IPCC Climate Change 2001: The scientific bias, in Houghton, J. t. and Ding, Y (eds.), Cambridge: Cambridge University Press, 2001. 
PAIXÃO, A. H. Que nem deserto. Correio Braziliense, Brasília, 15 de jun. de 2003. Mundo, p. 23.

RIBEIRO, M. do S. B. Variação Climática no Distrito Federal: componentes e perspectivas para o planejamento urbano. 2000, 133 f. Dissertação (Mestrado em Arquitetura) Faculdade de Arquitetura e urbanismo - Universidade de Brasília, Brasília, 03/12/2000.

SEMARH. Mapa Ambiental do Distrito Federal. Brasília: SEMARH, 2000. Escala: 1:100.000. 1 CD-ROM.

SILVA, F. A. M. Zoneamento Agroclimático. Brasília, 24 de março de 1998. Arquivo: disquete. Power Point. Palestra na Comissão Especial de Recursos Hídricos do Ministério da Agricultura.

SILVA, J. de F. da e D'ANGIOLELLA. A Climatologia aplicada na gestão de sistemas hidrológicos. Meio Ambiente, Brasília, n. 01, p. 40-45, 2002.

STEINKE, E. T. Considerações sobre variabilidade e mudança climática no Distrito Federal, repercussões nos recursos hídricos e a informação ao grande público. Brasília, 2004.196 p. Tese (Doutorado em Ecologia) Departamento de Ecologia, Universidade de Brasília. 12/11/2004.

STEINKE, V. A. Uso integrado de dados digitais morfométricos (altimetria e sistema de drenagem) na definição de unidades geomorfológicas no Distrito Federal. Brasília, 2003. 101 f. Dissertação (Mestrado em Geologia) Instituto de Geociências, Universidade de Brasília. 18/12/2003.

TUCCI, C. E. M. Impactos da variabilidade climática e dos usos do solo nos recursos hídricos. Brasília: ANA, 2002. 150 p. Relatório técnico. 